\title{
Benign Paroxysmal Positional Vertigo: Differential Diagnosis in Children
}

\author{
Sergio Carmona*1, Gabriela Grinstein ${ }^{2}$, Romina Weinschelbaum ${ }^{3}$ and Guillermo Zalazar ${ }^{4}$ \\ ${ }^{1}$ Department Neuro-otology, Fundación San Lucas para la Neurociencia, Argentina \\ ${ }^{2}$ Department of Neuro-otology. INEBA (Instituto de Neurociencias de Buenos Aires), Argentina \\ ${ }^{3}$ Department of Neuro-otology. INEBA (Instituto de Neurociencias de Buenos Aires), Argentina \\ ${ }^{4}$ Department Neuro-otology, Fundación San Lucas para la Neurociencia, Argentina
}

Received: January 20, 2018; Published: January 31, 2018

*Corresponding author: Sergio Carmona, Department of Neuro-Otology, Fundación San Lucas para la Neurociencia, Rosario, Santa Fe, Argentina, Email: sergiocarmona57@gmail.com

\begin{abstract}
We present the case of a 14-year-old girl, who presented with a positional vertigo of second duration, compatible with BPPV, but whose final diagnosis was a cavernoma in the cerebellum. We emphasize the importance of keeping in mind the different etiologies of vestibular syndrome in children.
\end{abstract}

Keywords: BPPV; Cavernoma; Episodic vestibular syndrome; Atypical BPPV

Abbreviations: BPPV: Benign Paroxysmal Positional Vertigo; Y.O: Year Old; NSAIDs: Nonsteroidal Anti-Inflammatory Drugs; HIT: Head Impulse Test; MRI: Magnetic Resonance Imaging

\section{Introduction}

BPPV is the most frequent cause of recurrent vertigo [1]. and its incidence increases with age [2]. As it is not a frequent event in children, a research on prevalence at a pediatric age found BPPV to be a cause of vertigo in a $3.88 \%$, and $3.4 \%$ [3]. For the age group of the patient here discussed. When we have to study a clinical picture with characteristics similar those to BPPV but a history, symptoms or clinical findings that are not the typical ones of a vertigo caused by a detachment of the otoliths, other canalithiasis or cupolithiasis non-related causes must be considered.

\section{Clinical Case}

Female patient, 14 y.o., with no relevant clinical history, who consults due to frontal headache, which partially improves with NSAIDs, positional vertigo that lasts seconds, permanent dizziness and neurovegetative symptoms: nausea and vomiting over the last week. Patient denies motion sickness; father refers having suffered from migraine in his adolescence, with no symptoms as an adult. No maternal history of migraine.

\section{Physical examination}

Bilateral negative bedside HIT. Negative head shaking. Patient presents geotropic nystagmus with both head rotations and greater nystagmus intensity with left turn (Figure 1). She presents neurovegetative symptoms during examination. It is interpreted as left horizontal canalithiasis. Lempert maneuver is performed. Evolution: symptoms improve 3 days later. Mild nystagmus persists with left head turn. Lempert maneuver is performed again. 4 days later patient is controlled: she refers having experienced a clinical improvement in the previous days. Today patient refers suffering from headache and dizziness when changing positions. She does not show positional nor did gaze evoke nystagmus. She presents horizontal nystagmus with right head turn, downbeat nystagmus with left head turn. A brain MRI is requested. MRI shows a heterogeneous lesion in right cerebellar hemisphere with signs of subacute bleeding compatible with right cavernoma (Figure 2).

\section{Discussion}

The patient was clinically presented as a geotropic lateral canal BPPV, yet, several atypical characteristics must be considered: the first one is age [2,3]. When there is no history of trauma. The patient's answer to the maneuvers applied was inconsistent and during the evolution she presented a vertical downbeat nistagmus which cannot be explained as due to changes related to severity. Carmona et al. recently presented a 4 [4], where they found a 
prolonged geotropic horizontal nystagmus accentuated to the side in which the patient had an acoustic neuroma and the authors speculate that, given the size of the tumor, there may be a dynamic compression of the vestibular nuclei which may generate variable information on the velocity storage mechanism or perhaps a true BPPV with an impaired velocity storage mechanism [5]. The presence of atypical BPPV must be studied with imaging studies, in this case of acoustic neuroma, hearing was symmetric and the only key were the atypical signs of the BPPV as explained. In this case, the acute onset of symptoms and the evidence of intracavernous bleeding may have an effect on the nodulus that regulates the nystagmic answer, which would also explain the change of direction in the nystagmus [6].

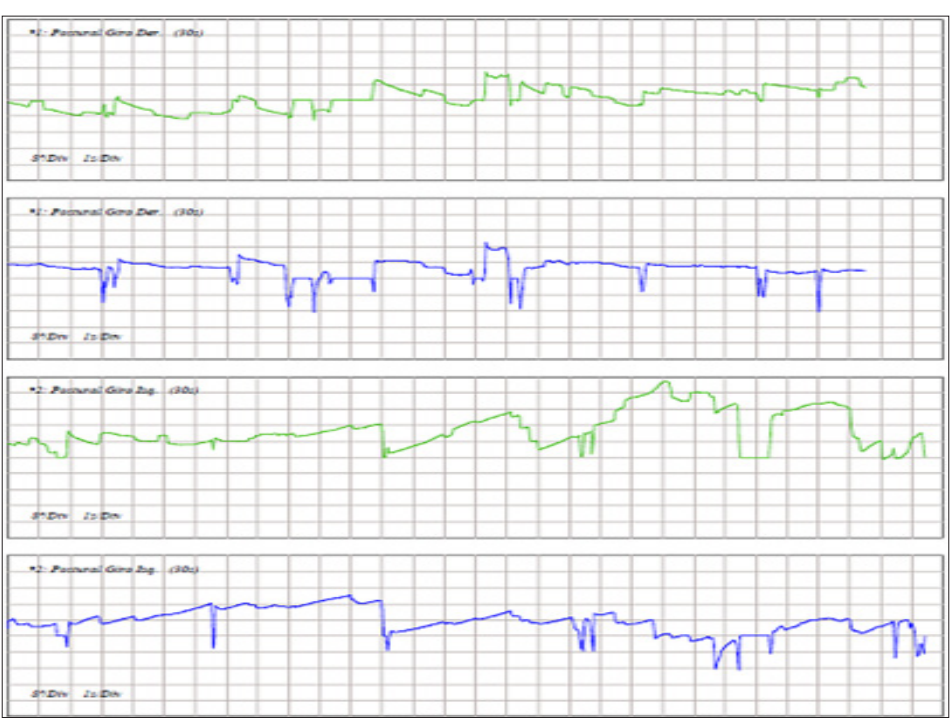

Figure 1: Videonistagmografía-Pruebas posicionales
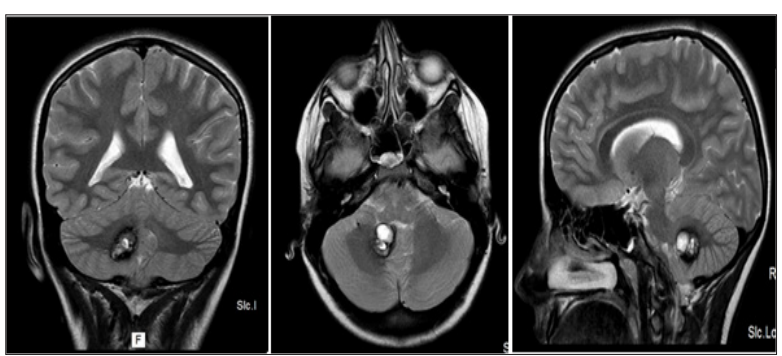

Figure 2: IRM ponderada en T2, cortes coronal axial y sagital

\section{Conclusion}

BPPV is uncommon at a pediatric age, mainly in the absence of a history of trauma, and this, together with the evolution led in our case to an etiologic diagnosis of central pathology.

\section{References}

1. von Brevern M (2013) Benign Paroxysmal Positional Vertigo. Semin Neurol 33: 204-211.

2. von Brevern M, Radtke A, Lezius F (2007) Epidemiology of benign paroxysmal positional vertigo: a population based study. J Neurol Neurosurg Psychiatry 78(7): 710-715.

3. Sommerfleck PA, Gonzalez Machi ME, Weinschelbaum R (2016) Balance Disorders in Childhood: Main Etiologies According To Age. Usefulness of the video head impulse test. Int J Pediatr Otorhinolaryngol 87: 148-153.

4. Carmona S, Zalazar R, Zalazar G (2017) Atypical Benign Paroxysmal Positional Vertigo in a Case of Acoustic Neuroma. J Otolaryngol ENT Res 8(5): 00261.

5. Herdman S, Clendaniel R (2014) Vestibular Rehabilitation ( $4^{\circ}$ edn). FA Davis Company, Philadelphia United States of America.

6. Walker MF, Tian J, Shan X (2010) The Cerebellar Nodulus/Uvula Integrates Otolith Signals for the Translational Vestibulo-Ocular Reflex. PLoS One 5(11):e13981.
(C) (i) This work is licensed under Creative

Submission Link: http://biomedres.us/submit-manuscript.php

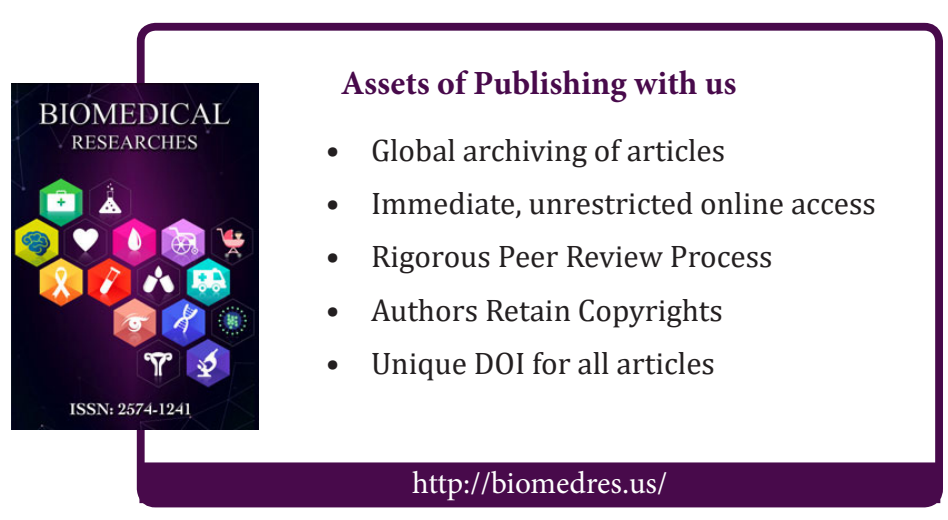

